\title{
A RANDOMIZED CONTROLLED TRIAL OF 5-DAY REGIMENT OF AZITHROMYCIN AND A 10-DAY REGIMENT OF CO-AMOXICLAV FOR TREATMENT OF ACUTE SINUSITIS
}

\author{
A. Rastegar Lari ${ }^{1}$, R. Alaghehbandan ${ }^{2}$
}

${ }^{1}$ Antimicrobial Resistance Research Center, Department of Microbiology, Iran University of Medical Sciences, Tehran, Iran, ${ }^{2}$ Faculty of Medicine, Memorial University of Newfoundland, St. John's, NL, Canada

Background: This study compared the efficacy of a 5-day regiment of Azithromycin (a macrolid antibiotic) with a 10-day regiment of Co-Amoxiclav (combination of an aminopenicillin with a betalactamase inhibitor) for the treatment of acute sinusitis.

Methods and materials: A total of 76 subjects with acute sinusitis, after meeting the inclusion criteria, were randomly divided into two groups, Azithromycin $(n=40)$ and Co-Amoxiclav $(n=36)$. One group received Azithromycin, $500 \mathrm{mg}$ in the first day and $250 \mathrm{mg}$ for 4 days and the other group received Co-Amoxiclav $625 \mathrm{mg}, 3$ times a day for 10 days. Patients were visited 4 times during the study (baseline, phone call, end of treatment, end of study) and regression/progression of their symptoms and their response to the treatment was evaluated.

Results: There was no significant difference between the two groups' demographic and clinical presentations. Duration of regression of the symptoms in the Azthromycin group was significantly shorter than the Co-Amoxiclav group (7.6 days versus 10.6, $\mathrm{p}=0.03$ ). Clinical success rate at end of the study was $80 \%$ for Azithromycin and $66.7 \%$ for Co-Amoxiclav ( $\mathrm{p}=0.025$ ). Clinical success rates among females in both groups seemed to be higher than males, but this difference was not statistically significant $(\mathrm{p}=0.13)$.

Conclusion: Findings of this study showed that Azithromycin regiment is more efficient, has less side effects, and required shorter treatment period. Patients were able to tolerate the medications better with a higher compliance and less economic cost than Co-Amoxiclav regiment. 